\title{
Los libretos de la protesta: un modelo para el estudio de la contienda política (Argentina, 1998-2005)
}

\author{
María Rosa Herrera, ${ }^{*}$ Clemente Navarro**
}

Perfiles Latinoamericanos, 25(50)

2017 | pp. $247-278$

DOI: $10.18504 / \mathrm{pl} 2550-012-2017$

\begin{abstract}
Resumen
El artículo propone un modelo para analizar la contienda política observando los elementos de la promoción de un evento de protesta (actor, demanda y target) e indagando en la conexión entre estos elementos. Se explora también en la construcción de una tipología de eventos de contienda atendiendo a las pautas de relación interna entre los actores, los motivos y el foco de la protesta. Finalmente, se aplica la propuesta al estudio de la contienda en Argentina entre 1998 y 2005, como caso ejemplar. El trabajo empírico se ha realizado siguiendo el protocolo de Protest event analysis y, en cuanto a la aproximación metodológica, se han desarrollado análisis de correspondencia múltiple y de clúster de serie temporal.
\end{abstract}

\begin{abstract}
This article proposes an analytical model to analyze political contention following the elements of promoting a protest event (actor, claims and target) and explore patterns of connection between these elements. Furthermore, explores the construction of a typology of contentious events focusing on the patterns of internal relationship between actors, motives and the target of the protest. Finally, this model is applied to the study of political contention in Argentina for period 1998-2005, as an exemplary case. For the empirical study protocol was followed Protest event analysis and methodological approach to multiple correspondence analyses, cluster and time series were developed.
\end{abstract}

Palabras clave: protesta, contienda política, Argentina, modelos, libretos de la contienda política. Keywords: Protest, political contention, Argentina, models, scripts of political contention.

* Doctora en Trabajo Social por la Universidad Pablo de Olavide. Contratada Doctora en el Departamento en Trabajo Social y Servicios Sociales de la Universidad Pablo de Olavide. Miembro del Centro de Sociología y Políticas Locales | mrherrer@upo.es

** Doctor en Sociología por la Universidad Complutense de Madrid. Catedrático de Sociología. Director del Centro de Sociología y Políticas Locales de la Universidad Pablo de Olavide | cnavyan@upo.es 


\section{Introducción ${ }^{1}$}

os estudios sugieren que ciertos elementos internos de un evento de protesta, tales como el actor que protesta, la demanda que realiza y el actor demandado, perfilan los contornos de la contienda política. Es decir, que la frecuencia e intensidad de los episodios contenciosos vienen condicionadas por los factores contextuales y por las características internas de la promoción del evento. En este artículo nos interesa profundizar en este último aspecto.

Pretendemos: a) proponer un modelo analítico para el estudio descriptivo de eventos de protesta tomando como eje de atención los elementos de la promoción del evento; $b$ ) aplicar dicho modelo a un caso ejemplar, el ciclo de protesta argentino de finales de la década de los noventa y comienzos de siglo XXI; c) a partir de ello explorar en las regularidades y patrones de concurrencia del quién, a quién y por qué protesta, para $d$ ) avanzar en propuestas analíticas que permitan caracterizar los eventos de protesta mediante el análisis de las relaciones existentes entre estos tres componentes. Esto último dará la pauta para determinar empíricamente si existen o no modelos específicos de eventos de protesta según el libreto por el que se desarrollan, así como su frecuencia en diferentes contextos.

Para cumplir nuestro objetivo utilizamos la base de datos "Dramatización de Contienda" de elaboración propia que recoge más de tres mil eventos de protesta ocurridos en Argentina en el periodo señalado, además de que hemos realizado distintos análisis descriptivos, inferenciales y multivariantes, y recurrido al de series temporales.

El artículo presenta, en primer lugar, un modelo analítico para examinar los aspectos de la promoción de los eventos de protesta, que aquí se han denominado elementos del libreto de la contienda. En segundo, se explica el trabajo de campo hecho y las decisiones metodológicas adoptadas. En tercero, se emprende una descripción de dichos elementos. Finalmente, se explora en los patrones de correspondencia de estos últimos, en sus regularidades y en la presencia de modelos de libreto, así como en sus pautas temporales.

\section{Los libretos de la dramatización de la contienda política: una propuesta de análisis}

Consideramos de interés abordar la contienda política usando la metáfora dramática, en la línea del denominado dramaturgical analysis, porque se trata

1 Los autores de este artículo agradecen las observaciones y sugerencias de los revisores anónimos; la incorporación de unas y otras ha conseguido un producto mejor acabado y más claro. 
de analizar un fenómeno que sucede ante nosotros como una escenificación (Tilly \& Tarrow, 2006; Tilly, 2008). Esto supone estudiar el evento de acción colectiva contenciosa del mismo modo que se observaría un acto dramático, es decir, atendiendo a los personajes, la acción y la situación. Más concretamente, una protesta supone la exposición pública en la que unos actores realizan ciertas demandas a otros actores mediante performances en las que se representan unos papeles, se desarrolla una coreografía (marcha, abrazo simbólico, acampada, etc.), se utilizan elementos escenográficos (banderas, carteles, símbolos) e incluso, en ocasiones, se recurre a vestuarios especiales (camisetas, caras pintadas, trajes, pañuelos, pasamontańas, etc.). Así pues, el evento de protesta es un acto dramático, una puesta en escena a cargo de unos actores que siguen un libreto (o guion).

Ahora bien, analíticamente cabe descomponer el evento de protesta en dos dimensiones: una relativa al hecho concreto que se desarrolla (la acción en términos dramatúrgicos) y otra referente a las características de la promoción de esa acción (situación y actores en términos dramatúrgicos). A la primera la entendemos como la puesta en escena de la dramatización, y configura el repertorio de confrontación que los actores despliegan. La segunda se refiere al quién, el qué y el a quién de la protesta (los actores y la situación que los vincula), y la hemos denominado el libreto de la acción colectiva contenciosa, pues contiene los elementos básicos que explicarían la puesta en escena de la contienda política.

Así, el libreto de la contienda es la combinación de los elementos inherentes a la promoción de un evento de protesta, mismos que la literatura denomina como sujeto, demanda y target. En este sentido, Tilly (2008) sugiere que el modo en que se combinen dichos elementos tendrá cierta influencia en las performances contenciosas, es decir, en la puesta en escena de la contienda política. De ahí la relevancia de atender a estas dimensiones tanto para caracterizar los procesos de promoción de la protesta, como para explicar la forma que esta última adopta. Pero, según la literatura, ¿qué rasgos adquieren estas tres dimensiones?

Respecto al sujeto, es decir, los grupos que promueven la protesta colectiva, en general se destaca la importancia de su estructura y lógicas organizativas, pues estas dan cuenta de los recursos disponibles para la movilización. ${ }^{2}$ Por lo común y en este sentido se identifican tres grandes modelos básicos: Modelo Movimiento de Base (MB), Modelo Grupo de Interés (GI) y Modelo Partido Político (PP) (Rucht, 1999). Estos tipos ideales se distinguen por cuatro

2 Este es un argumento central de la perspectiva de la movilización de recursos en la literatura sobre movimientos sociales; por ejemplo, McAdam (1999), McCarthy (1999), Clemens (1999), Voss (1999) o Rucht (1999). 
rasgos: estructura organizativa, principales recursos, estrategia de relación con sus miembros y, como producto de la conjunción de los anteriores, la eficacia de sus acciones en determinadas arenas políticas (Klandermans, 1989; Martí i Puig, 2002).

Primero, una mayor institucionalización de los rasgos estructurales (complejidad organizativa, grado de formalización, división de tareas y niveles de profesionalización) facilitaría que el actor dirima sus intereses en las arenas institucionales, aunque esto le quite flexibilidad de cara a nuevos reclutamientos o diferentes modos de acción. Segundo, en relación con los principales recursos cabría destacar las bases sociales, los contactos e incluso las posiciones estratégicas relativas a la reproducción de la sociedad, las funciones y actividades que asumen en cuanto a los procesos centrales del desarrollo de la vida cotidiana. Tercero, las estrategias de relación se refieren a la forma con la que se pretende lograr la movilización y participación de sus miembros, es decir, los sistemas de incentivos usados para el reclutamiento y la permanencia de la membresía. Sobre esto se suele distinguir entre grupos en los que priman incentivos selectivos o incentivos colectivos de carácter normativo y expresivo, pues ello informa del compromiso de participación que reclaman las organizaciones a sus miembros (Olson, 1965; Knoke \& Prensky, 1984; Knoke, 1990). Por último, la conjunción de diversas formas organizativas, recursos y sistemas de incentivos mostrarían la que podría denominarse capacidad o eficacia potencial del grupo para el desarrollo de diferentes estrategias externas en pos de la defensa de intereses colectivos (Klandermans, 1989; Martí i Puig, 2002).

En su sentido de tipos ideales, los MB contarían con una estructura organizativa reticular e informal, basada en la participación directa de sus miembros, principalmente mediante un sistema de incentivos afectivos y/o normativos. Esto provoca que su estrategia modal hacia el exterior sea la acción colectiva directa, o protestas sociales, porque, frente a su debilidad para canalizar sus demandas por vías institucionales, pueden recurrir con facilidad a repertorios de acción colectiva y a la expresión simbólica de su programa o demanda. La vía institucional, en cambio, sería modal para los GI, esto es, para aquellas organizaciones con estructura organizativa muy formalizada y sistemas de incentivos selectivos. Su principal recurso es la posición estratégica que ocupan en la reproducción de la sociedad y el acceso a los centros de toma de decisiones. Aunque su repertorio de acción modular sean la mediación y el lobby, sus recursos les permiten desarrollar procesos de movilización colectiva para dramatizar la contienda política. Por su parte y a diferencia de los anteriores, los pP tienen como recurso fundamental los apoyos electorales con el objetivo de ocupar cargos públicos, por tanto, sería menos previsible que recurran a la dramatización de la contienda. 
Tabla 1. Actores colectivos que protagonizan la dramatización contenciosa

\begin{tabular}{cl|lll}
\hline \multicolumn{2}{c|}{ Dimensiones } & Movimiento de base & Grupo de interés & Partido político \\
\hline Resgos estructurales & $\begin{array}{l}\text { Organización reticular. } \\
\text { No hay afiliaciones } \\
\text { formales a la red. }\end{array}$ & Organización formal piramidal. & $\begin{array}{l}\text { Organización formal } \\
\text { piramidal. }\end{array}$ \\
\hline Principal recurso & Bases sociales. & $\begin{array}{l}\text { Acceso a centros de decisión. } \\
\text { Posiciones estratégicas. }\end{array}$ & Apoyos electorales. \\
$\begin{array}{l}\text { Participación de los } \\
\text { miembros. }\end{array}$ & Directa. & No directa. & Esporádica. \\
\hline $\begin{array}{l}\text { Hacia el interior: sis- } \\
\text { temas de incentivos. } \\
\text { Hacia el exterior: re- } \\
\text { pertorios de acción. }\end{array}$ & Afectivos- Normativos. & Utilitarios. & Lobby-Protesta. & $\begin{array}{l}\text { Normativos. Utili- } \\
\text { tarios. } \\
\text { Ocupación de } \\
\text { cargos públicos. }\end{array}$ \\
\hline
\end{tabular}

Fuente: Elaboración propia con base en Rucht (1999) y Martí i Puig (2002).

La demanda puede analizarse a partir de dos criterios: $i$ ) la estructura de la necesidad subyacente y ii) su orientación. ${ }^{3}$ Lo primero informa sobre los bienes que se reclaman, los cuales van desde los materiales ligados a la seguridad personal, hasta los relacionados a la autoexpresión. Esto permite conocer la orientación axiológica subyacente en los movimientos de protesta, profundizando así en la vinculación de la teoría de la acción colectiva y la teoría del cambio cultural, al menos, en cuanto a la distinción que esta última hace entre orientaciones materialistas y posmaterialistas ${ }^{4}$ (Inglehart, 1977; Opp, 1990). El segundo daría cuenta de los niveles de frustración y urgencia, la posición desde la que el sujeto colectivo reclama derechos o provisiones. Por ello se entiende como defensa o conquista de derechos. $\mathrm{Y}$ a estas podría sumarse otro tipo que se define como manifestación de antagonismos, pues no se trata de reclamar derechos o bienes sino de expresar posiciones de conflicto frente a otro actor. Así, clasificamos la orientación de las demandas en tres categorías: reactiva, proactiva y antagónica (Tarrow, 1990).

Finalmente, acerca del target al que se dirige la acción contenciosa, en la literatura hay menos argumentos y evidencias sobre su caracterización e importancia para delinear el libreto (o procesos de promoción) de la protesta. Aun así cabe pensar que algunos rasgos del actor "demandado" se relacionan con decisiones del actor promotor del evento de protesta para lograr un impacto de su acción colectiva. Es posible distinguir dos criterios. Por un lado, la naturaleza del target, a saber: actores civiles (empresas, entidades de crédito, etc.)

3 Tarrow (1990) considera el sector, la orientación y la estructura de la demanda.

4 En este sentido, algunos estudios cross-national muestran el efecto sobre la protesta de los valores socialmente preponderantes, en términos de materialismo vs. posmaterialismo (Inglehart, 1977). Hay también una propuesta y análisis de la relación entre orientación axiológica materialista y formas de protesta (Opp, 1990). 
o autoridades públicas. Por el otro, el nivel jurisdiccional de las segundas, pues pueden dar cuenta de su capacidad para responder a la demanda y/o influir en procesos decisionales relacionados con la misma. Evidentemente, esto depende del nivel de descentralización en cada estado, de la capacidad de toma de decisiones que tenga cada nivel de gobierno.

Así, en sistemas más centralizados, se puede esperar que las protestas se orienten las más de las veces al nivel nacional porque allí reside una mayor capacidad de respuesta a demandas, y sobre todo porque el impacto en el target depende de la visibilidad de la protesta, la cual se garantiza dotándola de espectacularidad a fin de que reciba la suficiente atención por parte de los medios masivos de comunicación, aunque esto sesga el análisis de la contienda (Lipsky, 1965; Klandermans \& Goslinga, 1999). En sistemas menos centralizados, en cambio, la protesta tiende a orientarse a los niveles de gobierno subnacional.

Nuestra propuesta es que estos tres elementos utilizados para caracterizar la forma en que se promueve la protesta, se combinan de varios modos para poner de relieve distintas clases de libretos de la política contenciosa. Esto es, que hay ciertas relaciones que vincularían diferentes tipos de sujetos, demandas y targets. A su vez, las diferentes clases de libreto se vincularían con la frecuencia y la intensidad de las acciones contenciosas. Evidentemente, para explicar los eventos de protesta han de considerarse también factores contextuales, pero considerar el libreto permite conocer el desarrollo de estrategias concretas de protesta según la lógica (el libreto) de su promoción. O dicho de otra forma, en un mismo escenario, diferentes libretos darían lugar a diferentes puestas en escena. Si bien aquí no pretendemos analizar estas relaciones, sino solo aquellas que se dan entre las distintas dimensiones que dan cuenta del libreto.

\section{Gráfico 1. El evento de protesta desde la perspectiva de la promoción: el libreto de la contienda política}

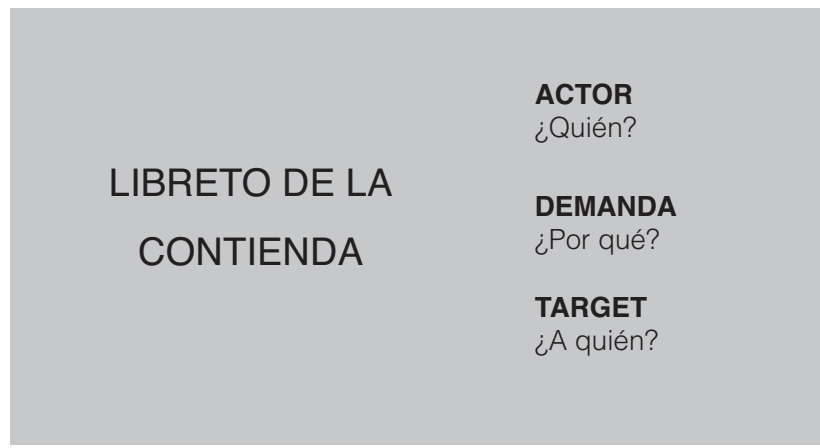

Fuente: Elaboración propia 


\section{Diseño metodológico}

Bajo las lentes analíticas descritas se ha estudiado la contienda política que se dio en Argentina a finales de la década de los noventa y principios del siglo XxI. Atendiendo a las enseñanzas de Tilly \& Tarrow (2006), hemos delimitado este periodo como un episodio contencioso de rasgos particulares que ofrece diversidad de actores, interacciones, demandas y repertorios a nivel empírico útiles para los propósitos de la observación sistemática, la comparación y explicación de este análisis. Entendemos que los eventos de protesta recolectados poseen conexión interna y despliegan una secuencia de interacción continua; de hecho se trata de un fenómeno que muestra claros rasgos de un ciclo de protesta (Herrera, 2008, 2012; Artese, 2012; Santella \& Scodeller, 2012). Un ciclo de protesta constituye un episodio especialmente rico para analizar la contienda, no solo porque comporta la intensificación de las interacciones contenciosas entre ciudadanía y Estado, sino también por la innovación — de actores, de formas contenciosas, de demandas - que se desarrolla en su seno. En otras palabras, el episodio delimitado analíticamente (ciclo de protesta argentino 1998-2005) es un conjunto amplio y diversos de eventos de protesta que permite aplicar nuestra propuesta sobre el libreto de las políticas contenciosas.

En específico, nuestro objetivo consiste en describir los rasgos básicos de cada elemento del libreto — actores, demandas y targets —, para luego identificar las pautas y patrones de relaciones entre ellos que conduzcan a caracterizar distintos clases de libreto. La idea es mostrar la valía de la propuesta en un caso ejemplar. Esto llevará a conocer si los resultados derivados de la aplicación de la propuesta se corresponden o son avalados por la literatura sobre el caso analizado y, por tanto, saber de su valía para aplicarla a otros más. Para analizar el ciclo de protesta argentino ya dicho, hemos aplicado la perspectiva metodológica del Protest event analysis (Koopmans \& Rucht 2002; Earl et al. 2004). La unidad de observación son los eventos de protesta ocurridos en Argentina durante el periodo 1998-2005, e incluso se elaboró una base de datos al respecto.

Como es común en esta perspectiva metodológica, se han analizado las fuentes de datos en las que se describen los eventos de protesta. Para ello se han validado diferentes fuentes de datos mediante la valoración comparada de las disponibles: bases de datos oficiales, documentación de movimientos sociales, prensa impresa y prensa on-line. La mayor cobertura y el número más amplio de eventos pertenecen a esta última. ${ }^{5}$ Asimismo, se compararon los datos de prensa diversa on-line bajo los criterios de cobertura territorial,

5 Un detallado análisis de los discursos construidos por la prensa escrita en relación a algunos eventos de protesta del ciclo que aquí se analiza se puede hallar en Artese (2011). 
volumen de tirada, sesgo ideológico y motor de búsqueda. Todo esto arrojó como resultado que Clarín.com representaba la fuente más apropiada para nuestro estudio. ${ }^{6}$

Así pues, la base de datos se construyó mediante un detallado trabajo que codifica la información de todos los eventos de protesta publicados en Clarín. com. De este modo quedó recabada la información de 3209 eventos de protesta. ${ }^{7}$ Y para cada uno de estos se han codificado, además del lugar y fecha del evento, aspectos de interés para este artículo (sujeto, demanda y target). Con ello se ha construido una base de datos con la que se han realizado los análisis aquí mostrados y se la ha denominado Base de Datos Dramatización de la Protesta (BdDP). ${ }^{8}$

En la tabla 1 se presenta esta información para los eventos analizados, en donde pueden verse las categorías elaboradas para los tres aspectos del concepto de libreto de la contienda política. En los siguientes apartados nos detendremos con mayor profundidad en cada dimensión del libreto a la vez que se des-

6 Además de los resultados de las pruebas pre-test, cabe mencionar otras características de la fuente de datos seleccionada. Para la World Association of Newspapers, los periódicos nacionales más influyentes son Clarín (con 800000 ejemplares en circulación y 1.2 millones los domingos) y La Nación (con 500000 ejemplares encirculación y 800000 los domingos). Clarín es el periódico de habla espańola más leído en América Latina. Pertenece a un conglomerado multimedia que posee dos estaciones de radio (Mitre y FM100), dos canales de televisión, el diario Olé (el único dedicado por entero a las noticias de deportes), y de participaciones en, al menos, tres periódicos provinciales, así como en la agencia de noticias DYN. Su tendencia editorial se la considera como moderada de centro-izquierda (World Association of Newspapers, 2001).

7 Atendiendo a la literatura especializada, se han escogido las unidades de observación cuando clasifican como evento de protesta que tengan las siguientes características: 1) acción colectiva (Harding, 1991), 2) que expresa una disconformidad (Gamson, 1975; Tarrow, 1990), 3) mediante un proceso de interacción socio-política (Jenkins \& Klandermans, 1995), 4) orientado este a conseguir la influencia política (Tarrow, 1999), 5) que es de carácter directo, 6) y supone alteración y 7) visibilidad pública, pero 8) que es discontinuo 9) y holístico. Así, las seis primeras características suponen que un evento de protesta entrańa un proceso de contienda política, la séptima indicaría que se escenifica públicamente, mientras que las dos últimas apuntan a que, aun pudiéndose descomponer en sus elementos básicos o relacionarse con otros eventos o procesos políticos, constituyen, cada uno de ellos, un caso o manifestación concreta y específica de dramatización de la política contenciosa.

8 Para recopilar las noticias que preveían eventos de protesta, como es común al análisis de contenido, se estableció un protocolo específico. En primer lugar, los patrones de búsqueda que, en concreto, fueron: a) palabras clave (protesta, movilización, demanda, demandaron, marcha, marcharon, piquete, manifestación, paro, manifestantes, cacerolazo); b) parámetros de extensión (titulares y texto); c) profundidad de búsqueda (todo clarín.com), y $d$ ) se determinó que la búsqueda fuera semanal y con esta se construyó un corpus de 2700 noticias, puesto que cada una de estas puede recoger más de una unidad de observación (el evento de protesta). Para limitar los sesgos de selección se aplicaron dos pre-test comparando los resultados de la herramienta de búsqueda on-line y los procedentes de una búsqueda manual para un mismo periodo — lo cual dio un producto positivo—, y además se ańadieron otras palabras clave para mejorar la identificación de eventos de protesta. 
cribirá su incidencia en el conjunto del ciclo de protesta y la correspondencia que muestran.

Tabla 2. El libreto de la contienda política: operacionalización de los conceptos

\begin{tabular}{|c|c|c|}
\hline Dimensión del libreto & Subdimensión (criterio) & Indicadores \\
\hline \multirow{3}{*}{ Actor } & \multirow{3}{*}{ Estructura organizativa } & Movimiento de Base \\
\hline & & Grupo de Interés \\
\hline & & Partido Político \\
\hline \multirow{7}{*}{ Demanda } & \multirow{4}{*}{ Bien que subyace } & Manutención \\
\hline & & Seguridad \\
\hline & & Socio-política \\
\hline & & Autorrealización \\
\hline & \multirow{3}{*}{ Posición del actor } & Reactiva \\
\hline & & Proactiva \\
\hline & & Antagónica \\
\hline \multirow{5}{*}{ Target } & Función socio-política & $\begin{array}{l}\text { Estado } \\
\text { Sociedad }\end{array}$ \\
\hline & \multirow{4}{*}{ Nivel jurisdiccional } & Local \\
\hline & & Provincial \\
\hline & & Nacional \\
\hline & & Supranacional \\
\hline
\end{tabular}

Fuente: Elaboración propia.

\section{Análisis empírico: descripción y tipos de libretos en Argentina (1998-2005)}

En este apartado exponemos los principales resultados de la investigación. En primer lugar, el análisis descriptivo de las categorías elaboradas. Los resultados se confrontarán con la literatura existente para el caso en estudio con el objeto de validarlos y contextualizarlos. En segundo lugar, mediante técnicas de análisis multivariables, presentaremos los diferentes tipos de libretos como combinaciones entre las distintas categorías de los tres aspectos (sujetos, demandas y targets), tratando de poner en relación los resultados de este artículo con la literatura existente.

La descripción de los elementos del libreto: quién, a quién y por qué se protestó en Argentina

En los párrafos que siguen se describen los eventos de protesta a partir de los elementos de su promoción, es decir, con base en las dimensiones del libreto de la contienda política. 


\section{Los actores protagonistas de la contienda política}

Tal como se ha discutido arriba, algunos actores parece que poseen más predisposición para dramatizar la contienda política debido a que su estructura y recursos organizativos condicionarían los repertorios de acción que desarrollan (Rucht, 1999) y a la eficacia de estos en diferentes arenas políticas (Klandermans, 1989). En este aspecto deberían destacar los $\mathrm{MB}$, y nuestros datos parecen confirmarlo: han promovido el $60 \%$ del total de los eventos de protesta analizados, casi el doble que los GI (37\%), con los PP (2\%) como el modelo minoritario. Pero, ¿ha sido así durante todo el ciclo?

El gráfico 2 recoge la frecuencia y el número total de eventos, señalando cuáles han sido promovidos por los tres actores. Muestra también la curva clásica de un ciclo: una fase de escalonamiento ascendente, que va desde los inicios del periodo en estudio hasta el último semestre del año 2000; una fase descendente, desde 2003 hasta los últimos registros, y la fase central, 2001 y 2002, de gran producción contenciosa, lo que la literatura denomina momento de locura (Zolberg, 1972). Pero además evidencia que la frecuencia de cada actor varía a lo largo del ciclo, mostrando que, tal y como señala Tarrow (1997), la dinámica de los ciclos de protesta tiene lugar mediante la tensión entre la cooperación y la competición de los actores de la contienda.

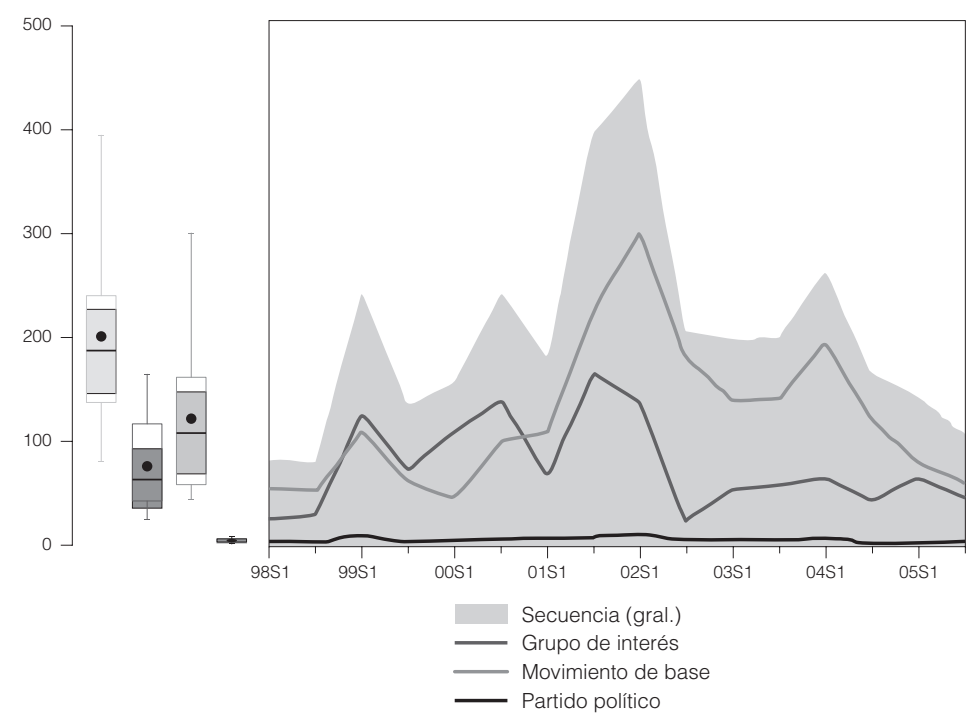

Nota: BdDP 1998-2005 (N 3902).

Fuente: Elaboración propia. 
De hecho, la correlación entre las series temporales de los tres actores muestra que los PP, aunque no realizan muchos eventos de protesta, suelen dramatizar la contienda política cuando lo hacen también los мв (correlación igual a 0.74). En cambio, los $\mathrm{GI}^{9}$ parecen dramatizar la contienda de forma más independiente, y en concreto, sintonizando más con los pp que con los MB (correlaciones iguales a 0.66 y 0.42 , respectivamente).

Por tanto, los partidos políticos, aunque dramatizan la contienda en menor medida, suelen hacerlo en el mismo momento que lo hacen otros, pero, en especial, en momentos específicos: durante 1999 y en la fase álgida del ciclo. El primero coincide con el desgaste del gobierno de Carlos Menem y la conformación de una corriente política nueva, la Alianza. ${ }^{10} \mathrm{El}$ segundo, con la disputa por el poder en el marco de la crisis de gobierno y posterior quiebre institucional que da lugar a la renuncia del presidente Fernando de la Rúa. ${ }^{11}$ Se trata pues, en ambos casos, de un proceso de movilización en el que se reconfiguran alianzas entre élites y partidos con vistas a procesos electorales.

En cambio, los GI y los MB muestran pautas temporales diferentes. Entre los primeros, la evolución de la frecuencia de protestas responde a procesos que ocurren en el seno del movimiento sindical, en concreto, la emergencia y consolidación de nuevas federaciones sindicales que apuestan por la confrontación en contraposición a una pauta de intermediación de corte corporativista más frecuente de la Central General de Trabajadores (Farinetti, 1999; Murillo, 1997). Así pues, el primer pico (en 1999) consiste en protestas promovidas mayoritariamente por organizaciones que se desenganchan de la Central General de Trabajadores oficialista ${ }^{12}$ y se enfrentan al gobierno de Carlos Menem. ${ }^{13} \mathrm{El}$ segundo pico (2000 y 2001) coincide con el gobierno de la Alianza: organizaciones sindicales tradicionales, que no cuentan con su histórico aliado entre las élites gubernamentales (peronistas), promueven el mayor número

9 Un buen trabajo sobre las organizaciones sindicales y su acción colectiva se encuentra en Maceira (2011).

10 En 1997, la Unión Cívica Radical (UCR) y el Frente País Solidario (FrePaSo) integraron la Alianza por el Trabajo la Justicia y la Educación, conocida como La Alianza. Esta ha sido la marca con la que ambas agrupaciones políticas se presentaron a diversas contiendas electorales y que les procuró el sillón de Rivadavia en 1999. Para mayor detalle de la dinámica interna y performances legislativas del grupo parlamentario, véase Silva (2015). Un análisis del desarrollo de la formación y su impacto en las elecciones generales de 1999 y del sistema de partidos en general, se puede consultar en Camou (2000).

11 Político de la Unión Cívica Radical, alcanza la presidencia de la mano de la Alianza en 1999 y renuncia a su cargo en 2001 tras un violento estallido ciudadano.

12 Se trata fundamentalmente de sindicatos aglutinados bien en el Movimiento de Trabajadores Argentinos (мтА), bien en la Central de Trabajadores Argentinos (СтА).

13 Presidente de Argentina entre 1989 y 1999 por el Partido Justicialista (coloquialmente, peronismo). 
de protestas. A esto debe añadirse las formaciones sindicales que apoyaron ${ }^{14}$ la conformación de la Alianza y no vieron satisfechas sus demandas gremiales durante el gobierno de aquella. Finalmente, cabe destacar que la protesta que encabezan los grupos de interés decae una vez que el gobierno regresa a manos del Partido Justicialista en 2002.

En cuanto a los MB, incrementan significativamente su actividad contenciosa a partir de finales de 2001 y son los últimos en disminuir la frecuencia de la protesta (véase arriba el gráfico 2).

\section{Las demandas de la contienda política: bienes y orientación}

Cabría señalar que el ciclo de protesta argentino se caracterizó por la gran importancia de las demandas de manutención y por su orientación reactiva (Schuster \& Pereyra, 2001; Giarracca \& Gras, 2001). Pero veamos con más detenimiento cuales son los motivos de las protestas sociales en el contexto del ciclo.

Tabla 3. Demandas según el bien subyacente

\begin{tabular}{llcr}
\hline & & Frecuencia & Porcentaje \\
\cline { 3 - 4 } & Manutención & 1764 & 55.0 \\
& Seguridad & 528 & 16.5 \\
& Sociopolítica & 698 & 21.8 \\
& Autorrealización & 94 & 2.9 \\
& Total & 3088 & 96.2 \\
\hline Perdidos & Sistema & 125 & 3.9 \\
Total & & 3209 & 100.0 \\
\hline
\end{tabular}

Fuente: Elaboración propia con información de la BdDP 1998-2005.

En concreto, las demandas en torno a la manutención aparecen en algo más de la mitad de los eventos de protesta (55\%); claramente relacionadas con el eje axiológico materialistas, son las más importantes para los eventos de protesta que analizamos. Después se encuentran las de índole social (22\%), las de seguridad (17\%), y por último, las de autorrealización (3\%). En consecuencia, parece que las demandas que subyacen a la dramatización de la contienda en Argentina entre 1998 y 2005 se articulan, sobre todo, alrededor del eje axiológico materialista: el $74 \%$ de los eventos de protesta del periodo se orienta a

14 Diversos sindicatos del gremio de docentes, entre otros. 
conseguir bienes públicos destinados a satisfacer la manutención y la seguridad, lo que es bastante constante para todo el ciclo.

Tabla 4. Demandas según la posición del actor

\begin{tabular}{lcc}
\hline Tipo de demanda & Eventos según demanda & \\
\hline & Freq. & $\%$ \\
\hline Reactiva & 1376 & 42.87 \\
Proactiva & 774 & 24.11 \\
Antagónica & 824 & 25.67 \\
Total & 2974 & 100 \\
\hline
\end{tabular}

Fuente: Elaboración propia con información de la BdDP 1998-2005.

La literatura señala que el argentinazo $0^{15}$ surge como reacción a la acentuación de un contexto político neoliberal de ajuste, desmantelamiento del Estado de bienestar, y restructuración y privatización de la administración pública. De hecho, según nuestro análisis, el $43 \%$ de las protestas se promueven desde posiciones reactivas, es decir, defensivas, mientras que el 26\% desde posiciones antagónicas para manifestar oposición a otro actor o colectivo. Solo el $24 \%$ de las protestas se promueven desde posiciones proactivas buscando ampliar derechos.

\section{Los actores interpelados}

¿A quién se interpela en los eventos de protesta? Nuestro análisis muestra que, mayoritariamente, a un actor gubernamental, pues $84 \%$ de los eventos lo tiene como target, mientras que solo el $16 \%$ se orientan a un actor social. ${ }^{16}$

Considerando en particular el ámbito estatal como target de la contienda, las protestas se dirigen fundamentalmente a los poderes ejecutivos de los diferentes niveles jurisdiccionales durante todo el periodo (el 84\%), y es mucho menor el reclamo dirigido al poder judicial $(10 \%)$ y al legislativo $(6 \%)$.

15 Se identifican de este modo porque el epicentro del ciclo ocurre a finales de 2001 y comienzos de 2002 con eventos de protesta de gran envergadura que la literatura ha denominado argentinazo.

16 En cuanto al sector social, califican las clásicas protestas articuladas por organizaciones sindicales enfrentadas a la patronal, o bien por reivindicaciones ambientalistas, ya sea de organizaciones ecologistas o pobladores cuyos intereses se ven perjudicados por ciertas empresas. En cuanto a las que tienen al sector financiero como target, son las conocidas campańas de protestas "poscorralito financiero" patrocinadas por las organizaciones de ahorristas a partir de 2002. Finalmente, entre las dirigidas a los partidos políticos se cuentan la campańa de protesta del "que se vayan todos". 
Tabla 5. Actor demandado según función sociopolítica

\begin{tabular}{lllc}
\hline Sector & \% Eventos de protesta & Ámbito & \% Eventos de protesta \\
\hline Estado & 84.25 & Ejecutivo & 70.80 \\
& & Legislativo & 4.70 \\
& & Judicial & 8.70 \\
Sociedad & 15.78 & Político & 3.20 \\
& & Empresario & 10.80 \\
Total & 100 & Financiero & 1.70 \\
\hline
\end{tabular}

Fuente: Elaboración propia con información de BdDP 1998-2005.

Tabla 6. Actor demandado según nivel jurisdiccional

\begin{tabular}{lcc}
\hline & Frecuencia & Porcentaje \\
\hline Local & 265 & 10.1 \\
Provincial & 794 & 30.4 \\
Nacional & 1468 & 56.2 \\
Supranacional & 87 & 3.3 \\
Total & 2614 & 100.0 \\
\hline
\end{tabular}

Fuente: Elaboración propia con información de BdDP 1998-2005.

Llama la atención el bajo porcentaje de protesta que se dirige al legislativo, pues es la arena natural del debate político. En este sentido, destacan tres mecanismos que operan en la política argentina: su marcado presidencialismo (Lanzaro, 2001; Novaro 2001), la naturalización de los decretos de necesidad y urgencia como instrumentos normativos con validez de ley, ${ }^{17}$ y una cultura política populista que incentiva la relación directa y personalista entre "el pueblo" y "el líder" (Nun, 1998; Laclau, 2005).

Si se atiende a la jurisdicción del target, domina el ámbito nacional (56\%), ${ }^{18}$ seguido del provincial (30\%) y el local (10\%), así como los niveles supranacionales (3\%). Ahora bien, su evolución durante el periodo que abarca el ciclo de protesta muestra pautas específicas. Puede apreciarse una relación negativa

17 La Convención Constituyente (1994) reguló las atribuciones del Poder Ejecutivo nacional y recoge los "decretos de necesidad y urgencia" (art. 99.3) solo para "circunstancias excepcionales"; entre 1989 y 1998, Menem firmó 472 de ese tipo de decretos (Ferreira \& Goretti 1998).

18 En parte, el mayor número de eventos de protesta cuyo target es el Estado nacional responde al sesgo de selectividad de todos los estudios con los periódicos como fuente. Una buena reflexión al respecto se recoge en Earl et al. (2004). No obstante, se han realizado pruebas en la línea de lo señalado por Koopmans \& Rucht (2002) que garantizarían que la base de datos con la que se ha trabajado tiene controlados los sesgos de selectividad y descripción. Para mayor información, véase Herrera (2010). 
entre la curva de los niveles nacional y provincial (correlación igual a - 0.87 para todo el periodo). ${ }^{19}$

La estructura de oportunidad política, como grado de acceso al centro (Navarro, 1999), pudiera explicar este comportamiento: en cuanto al target provincial, su mayor frecuencia coincide con los periodos de menor acceso al centro de decisión nacional por parte de la mayoría de los gobiernos provinciales, encabezados por el Partido Justicialista, y por tanto, en la oposición al nivel federal, liderada por la Alianza (2000-2001). De modo que se trataría de un escenario favorable para presionar a los gobiernos provinciales, ya fuera porque no cuentan con el apoyo del nivel federal y este puede estar más predispuesto a distribuir bienes y recursos, ya porque los gobiernos provinciales son más permisivos o incluso incentivan la protesta para presionar al federal.

En este sentido, resalta que el sistema de gobierno federal permite el control y la cooperación entre el Estado nacional y las provincias que lo conforman, pero también da pauta a dinámicas de competición. Por otro lado, el marco constitucional en el que descansa el federalismo argentino no es muy preciso en lo que se refiere a las funciones y responsabilidades de cada nivel de gobierno y ha estado sujeto a importantes redefiniciones de competencia en las década de los setenta y los noventa, y no ha sido acompañado de una descentralización financiera. Todo ello ha hecho más compleja la relación nación-provincias-municipios (Jiménez \& Cetrángolo, 2004).

En general, estos análisis muestran que los actores promotores de la protesta la dirigen principalmente al target con capacidad para responder a sus demandas, aunque de forma selectiva entre el nivel federal y el provincial, en función de los aspectos contextuales que dan cuenta de la estabilidad de estos o las alianzas existentes entre ellos.

\section{Acción colectiva contenciosa y regularidades en la protesta argentina}

Los análisis previos muestran que, en líneas generales, en el ciclo de protesta en estudio prevalecen los MB como actor demandante, las demandas materialistas hechas desde posiciones reactivas, y la preeminencia del Ejecutivo y del Estado nacional como actor interpelado. Este sería el libreto genérico para

19 El target nacional registró un incremento importante a partir del segundo semestre de 2001, pero también muestra picos en 1999 y 2003; el primero de estos coincide con el "momento de locura" del ciclo donde el principal objeto de demanda es el Estado nacional y de este, preponderantemente, el Ejecutivo. Los otros momentos coinciden con los comicios a presidente de la república, mismos que suponen la apertura de las oportunidades políticas a la posibilidad de influir sobre las agendas electorales (McCarthy, 1999). 
todo el ciclo analizado que, tal y como hemos ido indicando, parece coincidir con otras investigaciones sobre la misma temática.

En este sentido, la literatura ha llamado la atención sobre la existencia de al menos dos grandes modelos de acción colectiva en las sociedades latinoamericanas (Garretón, 2001). Por un lado, un modelo clásico surgido en la década de 1930 en el que los Gi han sido los principales articuladores de demandas, con el Estado nacional como interlocutor por antonomasia y dando lugar a procesos de concertación neocorporativista más o menos formales. Estos gi fueron los actores centrales del modelo de acumulación que patrocinó, en el campo sociopolítico, un periodo de expansión de ciudadanía mediante la ampliación de derechos sociales y políticos a los sectores vinculados a la producción industrial ${ }^{20}$ y que quiebra en la década de 1990 (Cavarozzi, 1991; Paramio, 2000).

El otro patrón de acción colectiva se corresponde con el denominado modelo societal, emergente a resultas de las grandes transformaciones de la era neoliberal. En este modelo son más importantes los movimientos sociales o, al menos, surgen actores nuevos frente a los grupos de interés de matriz sindical (Schuster $\&$ Pereyra, 2001). Esto se da en un contexto de cambios socioeconómicos e institucionales muy relevantes (Palermo, 1990; Sidicaro, 2004). Los reiterados ajustes estructurales de los noventa abren el paso a penosos procesos de desciudadanización, con los se relacionan las demandas de corte reactivo (Giarraca \& Gras, 2001; Schuster \& Pereyra, 2001). Además, se ha producido una progresiva descentralización de las políticas de bienestar social hacia los ámbitos provinciales y locales, lo que los coloca en el ojo de la tormenta (Lo Vuolo \& Barbeito, 1998; Bustelo \& Minujin, 1997) y los convierte en foco de las protestas con demandas reactivas (principalmente de contenido sustantivo) que, como se ha mostrado, las promueven sobre todo los movimientos de base. ${ }^{21}$

La literatura específica que aborda el caso argentino destaca también este proceso de trasformación de la matriz de acción colectiva contenciosa. Así sucede con la emergencia de organizaciones que se articulan con base en identidades no vinculadas a la ciudadanía sociolaboral, y su devenir en actores colectivos supone una novedad para la cultura política argentina (Farinetti, 2002). En concreto, y de modo paradigmático, es relevante el surgimiento

20 Sobre las concertaciones corporativistas y neocorporativistas, véase Giner \& Pérez (1979) y Schmitter (1974); sobre sus rasgos en Latinoamérica, y en especial en Argentina, Paramio (2000) y Cavarozi (1991).

21 Vázquez \& Falleti (2007) estudian con minuciosidad el profundo proceso de deslegitimación de la política menemista, las expectativas ciudadanas (y su ruptura) surgidas con la propuesta política de la Alianza y su impacto en la acción colectiva contenciosa de ese periodo. Todo esto complementa, desde el punto de vista de los actores, el ciclo de protesta que aquí se analiza. 
de un espacio pluriorganizacional denominado movimiento piquetero, mismo que debe ser comprendido en un contexto de aumento creciente del desempleo, retraimiento de la economía productiva en general y privatización de empresas públicas.

La construcción de este espacio ${ }^{22}$ en el que convergen fundamentalmente, aunque no de forma exclusiva, organizaciones de desempleados provenientes del cierre de explotaciones industriales y privatizaciones de empresas públicas con anclajes territoriales, es compleja e influye con intensidad en el mapa de la contienda política según su desarrollo va condicionando la expansión del conflicto. Así, su surgimiento e incidencia viene estrechamente ligado a los territorios provinciales. En parte, la interacción de estas organizaciones con el gobierno subnacional está condicionada por la presencia y robustez de una compleja red de apoyos socioeconómicos que resultan de la aplicación de políticas de asistencia focalizadas que pretendían, sin éxito, paliar las manifestaciones de la crisis y contener el conflicto social. La supervivencia de estos flujos económicos provienen, en general, de financiamientos habilitados (o no) por el gobierno nacional (Farinetti, 1998); de este modo, la triangulación (movimientos piqueteros-gobierno provincial-gobierno nacional) supone un nivel de complejidad creciente y marca una pauta progresiva de nacionalización del conflicto de este agente colectivo (Natalucci, 2010).

Todo ello clarifica, por un lado, que los sindicatos pierden el monopolio como actores de agregación de identidades sociales y de representaciones de intereses (Delamata, 2002) y, por otro, la creciente diversificación de los objetivos de la protesta toda vez que se rompe la matriz de centralidad estatal "nacional” como eje de articulación de un modelo de acumulación y legitimación (Farinetti, 2002).

En cierta medida, esta distinción entre modelo clásico y modelo emergente en las sociedades políticas latinoamericanas, y la argentina en especial, guarda un paralelismo con la distinción genérica entre contienda contenida y contienda transgresiva (McAdam, Tarrow \& Tilly,2005). En la primera, los actores principales son "autoidentificados", o previamente existentes y reconocidos como interlocutores de la sociedad civil, y son el eje de las reivindicaciones convencionales. En la segunda, los actores protagonistas son nuevos, emergentes y presentan reivindicaciones y formas de protesta con menos precedentes.

A estos dos modelos cabría añadir un modelo propio de los partidos políticos, cuando tratan de combinar oposición institucional y no institucional (Pasquino, 1996). Esto suele darse en ambientes políticos e institucionales con rasgos de centralización y patrimonialización, así se apropian de las calles para

22 Para un detallado análisis del movimiento piquetero, véase Natalucci (2010). 
realizar reclamos que no pueden hacer valer en la arena parlamentaria. Esto provoca que sus demandas se concentren en recoger la insatisfacción con el sistema institucional o sus actores (la Corte Suprema de Justicia o el "que se vayan todos", es decir, de antagonismo) y que sus targets sean, además de autoridades públicas nacionales, actores supranacionales reguladores de la economía nacional (campañas contra el sistema económico, el FMI o la globalización).

\section{Coordenadas de la contienda y tipos modales de libreto de protesta}

¿Se producen estos tres modelos en el ciclo de protesta analizado? ¿Qué importancia relativa tienen?, ¿En qué momento del ciclo? Para dar respuesta a estas preguntas se ha concretado un estudio de correspondencias múltiples con las tres variables que identifican los elementos del libreto. Una vez analizadas e interpretadas las dimensiones resultantes de ello se ha aplicado un análisis de conglomerados a partir de las puntuaciones de cada evento de protesta a fin de identificar claramente a qué tipo (clúster) pertenecería. Esto llevará a identificar los modelos de libretos, su importancia relativa, y posteriormente, su distribución en el tiempo.

El análisis de correspondencias múltiples evidencia dos grandes dimensiones, las cuales se han representado en el gráfico 3 que muestra la localización de las categorías de las variables incluidas. ${ }^{23} \mathrm{El}$ eje horizontal contrapone aspectos sustantivos y expresivos de la contienda, en concreto, las demandas reactivas y proactivas (parte izquierda del gráfico) frente a las de antagonismo (parte derecha del gráfico). El eje vertical contrapone a los actores característicos de la contienda contenida (GI y PP) a los de la contienda transgresiva (movimientos de base), en línea con lo que señalan McAdam, Tarrow \& Tilly (2005). La primera (abajo en el gráfico) la desarrollan actores "autoidentificados"24 (GI y PP) y posiciones de demanda clásicas de la política democrática en general y la argentina en particular (ampliar la dimensión ciudadana y la competición)

23 El alfa de Cronbach para la primera es de 0.473 y para la segunda de 0.332 . La varianza explicada de las dos dimensiones introducidas es de $92 \%$ (0.915). Para la primera dimensión es de 0.487 y para la segunda de 0.28 . Para aquellos casos (eventos) que no tenían información para alguna variable, se ha imputado la moda de esta. Se han realizado análisis generando una categoría adicional para los casos missing, así como otros sin realizar la imputación, habiendo obtenido resultados similares en ambos. Se muestra aquí el análisis con imputación que permite analizar, y posteriormente clasificar en el clúster, a todos los casos (eventos).

24 McAdam, Tarrow \& Tilly (2005) señalan como rasgos distintivo entre la contienda contenida y la transgresiva que en la primera algunos de los actores que hacen el reclamo se consideran políticamente constituidos, mientras que en el segundo grupo clasifican aquellas en las que al menos uno de los actores es emergente y emplean acciones y metodologías innovadoras. 
y está centrada en un target federal (nacional). La segunda (zona alta del gráfico) representa las nuevas configuraciones: actores novedosos que interpelan a instituciones subnacionales (local y provincial), presentan principalmente demandas reactivas, es decir, desde posiciones de vulnerabilidad, pero también muy cercanas a las demandas de antagonismo, dando cuenta así de una diversificación en su seno.

Gráfico 3. Los elementos del libreto de confrontación. Análisis de correspondencias múltiples. Categorías en el primer plano factorial

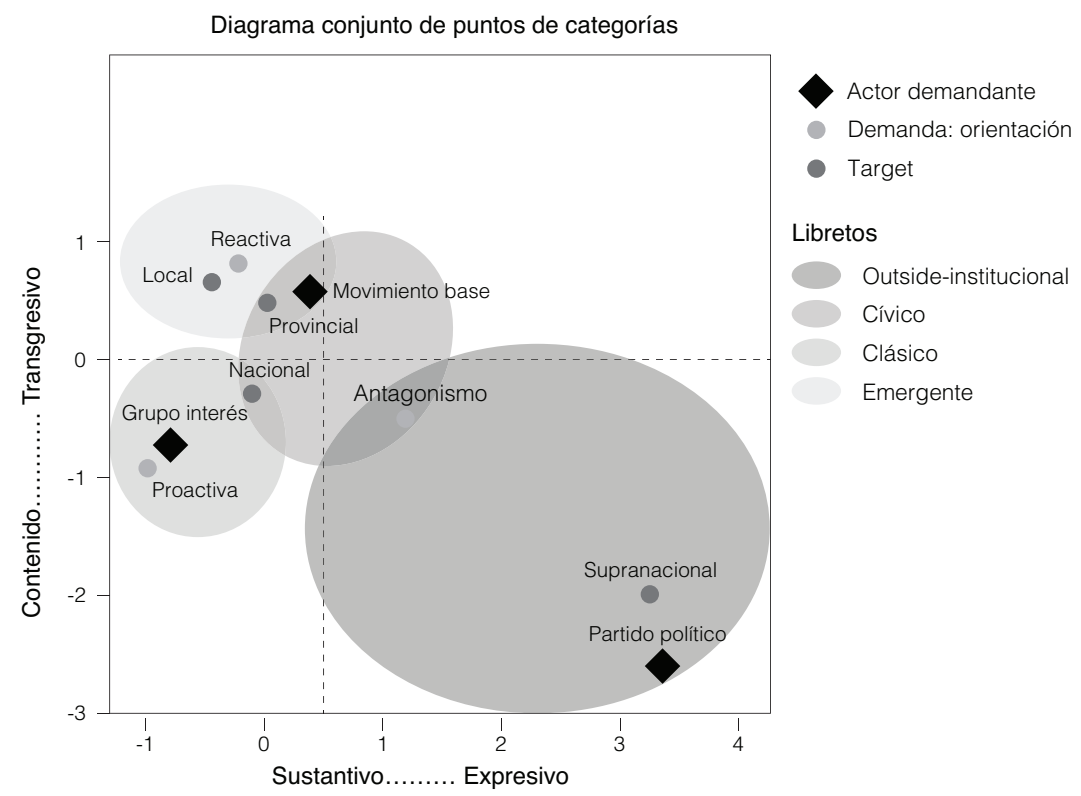

Normalización principal por variable

Fuente: Elaboración propia con información de BdDP 1998-2005.

La aplicación del análisis clúster a las puntuaciones de cada evento de protesta en esas dos dimensiones muestra que existen cuatro tipos de libreto; las medidas de cada uno en las dos dimensiones se recogen en la tabla $7 .{ }^{25}$

25 Hemos aplicado técnicas de clúster no jerárquico (K-means); y se han hecho pruebas con tres clústeres. Los resultados son similares y han identificado los modelos clásico, emergente y de los partidos. No obstante, la solución presentada aquí (4 clústeres) permite identificar la diversificación de dos modelos emergentes, lo que se corresponde mejor con los análisis descriptivos previos (tablas de contingencia). 
Dos de ellos son protagonizados por actores autorrealizados. Por un lado, el libreto clásico que desarrollan los GI presentando demandas proactivas a nivel de gobierno nacional. Por otro, el que encabezan los pp, enfocado en demandas competitivas orientadas a ámbitos supranacionales. Los otros dos modelos son protagonizados por мв. Por un lado, aquellos que toman como target ámbitos subnacionales en torno a demandas reactivas, y por otro, más minoritario, las demandas de antagonismo que se presentan al ámbito nacional y, si acaso, al supranacional.

Tabla 7. Los modelos de libreto. Centros (medias) de los conglomerados finales y tamaño sobre total de la muestra

\begin{tabular}{lcccc}
\hline & Cívico & Emergente & Clásico & $\begin{array}{c}\text { Outside- } \\
\text { institucional }\end{array}$ \\
\hline $\begin{array}{l}\text { Dimensión } \\
\text { Expresiva/Sustantiva }\end{array}$ & .90 & -1.01 & -.02 & 3.22 \\
$\begin{array}{l}\text { Dimensión } \\
\text { Transgresiva/Contenida }\end{array}$ & -.24 & -.76 & .99 & -2.19 \\
$\%$ sobre total de la muestra $(\mathrm{n})$ & 22.60 & 32.01 & 41.33 & 4.10 \\
\hline
\end{tabular}

$\mathrm{N}=3208$ Método: K-media.

Fuente: Elaboración propia con información de BdDP 1998-2005.

Así pues, se evidencia claramente un libreto clásico-sindical, propio de los GI y vinculado al target nacional mediante demandas proactivas. Este representa el $32 \%$ del total de los eventos de protesta en estudio. Asimismo, es evidente un libreto que, aunque minoritario (no más del 4\%), asocia a los Pp con un target supranacional mediante demandas competitivas. Se trataría de un libreto que pudiéramos denominar outside-institucional, pues se trata de un guion contencioso que surge por la imposibilidad de reivindicar temas en los foros propios de representación de intereses por sus actores característicos. Se trata de jugadores desplazados de su campo de juego que optan por la contienda en la calle, como estrategia para ampliar los apoyos electorales.

El otro libreto mayoritario ( $41 \%$ de los eventos de protesta) lo encabezan los мв con demandas reactivas dirigidas a niveles subnacionales, al que debe sumarse el menos numeroso $(22 \%)$ cuando estos presentan demandas antagónicas. Ambos libretos son emergentes en el sentido de lo planteado por Garretón (2001), pero el primero correspondería a un subgrupo con un sesgo socioeconómico, es decir, que surge por las transformaciones socioeconómicas y políticas de la década de los noventa; mientras que el segundo corresponde a un subgrupo de corte cívico. Los rasgos básicos de cada libreto y su peso en el total de eventos de protesta analizados se muestran en la tabla 8 . 
Tabla 8. Libretos de la dramatización contenciosa

\begin{tabular}{|c|c|c|c|c|}
\hline \multirow{2}{*}{$\begin{array}{l}\text { Libretos } \\
\text { (clúster) }\end{array}$} & \multicolumn{3}{|c|}{ Rasgos } & \multirow[t]{2}{*}{$\%$} \\
\hline & Actor & Demanda & Target & \\
\hline Clásico & Gl & Proactiva & Nacional & 32.01 \\
\hline Emergente & MB & Reactiva & Local / Provincial & 41.33 \\
\hline Cívico & MB & Antagonismo & Nacional/Supranacional & 22.60 \\
\hline Outside-institucional & PP & Antagonismo & Supranacional & 4.1 \\
\hline
\end{tabular}

$\mathrm{N}=3208$.

Fuente: Elaboración propia con información de BdDP 1998-2005

El análisis descriptivo de la frecuencia temporal de cada libreto muestra la preeminencia del emergente durante todo el periodo, seguido por el clásico (gráfico 4). Estos constituyen las formas principales del guion de la dramatización de la contienda política en Argentina entre 1998 y 2005. No obstante, vale señalar algunas apreciaciones. El libreto clásico describe una tendencia en forma de U: es dominante al inicio del ciclo (en 1999), decrece en los años de mayor conflictividad, y recupera el protagonismo al final del periodo (en 2005). Esto es propio de periodos en los que se da un mayor grado de normalización en los sistemas tradicionales (clásicos) de representación de intereses corporativistas. El "momento de locura" es más bien de los MB.

Gráfico 4. Libretos de la dramatización contenciosa en perspectiva temporal (1998-2005).

Porcentaje sobre el total de eventos en cada unidad temporal

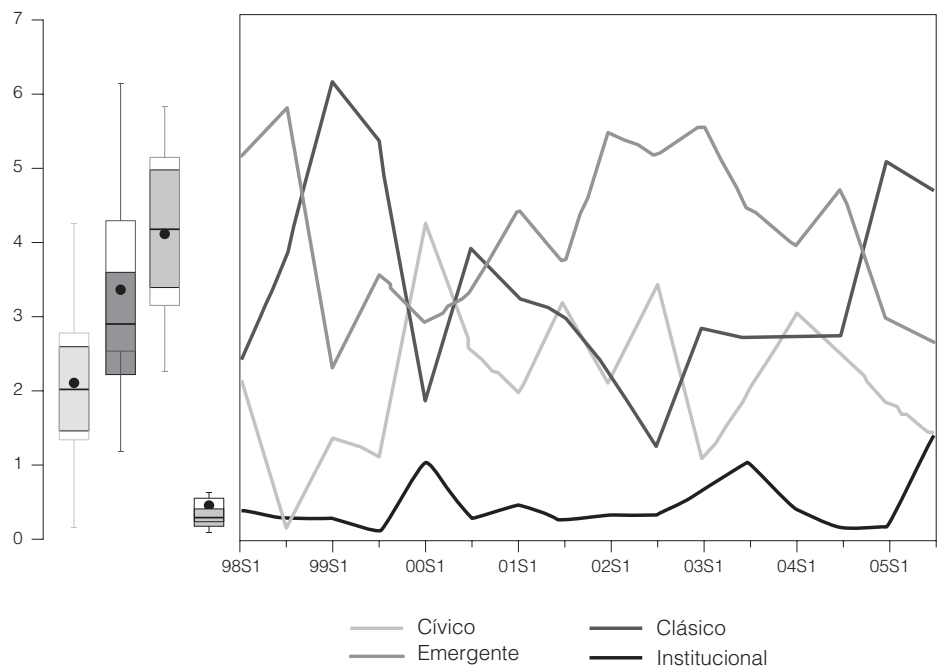

Fuente: Elaboración propia con información de BdDP 1998-2005. 
Finalmente, aunque el libreto outside-institucional tiene una presencia muy pequeña durante el ciclo, destaca que sus picos más relevantes se dan en 2000, 2003 y 2005, el primero asociado a los cambios en la estructura de oportunidades políticas producidos por las elecciones que llevaron al gobierno a la Alianza, lo que generó fragmentación vertical y apertura de estructura de oportunidades. En suma, se trata de protestas que repudiaban al Fondo Monetario Internacional, que entonces negociaba un nuevo ajuste fiscal para Argentina. El pico de 2003 se asocia a acontecimientos políticos y militares transnacionales, son protestas contra la guerra en Irak. El de 2005, por su parte, se asocia a dos episodios: a) las campañas de protesta que repudiaban la visita del presidente estadounidense George Bush en la IV Cumbre de las Américas celebrada en Mar del Plata, y b) la campańa de protesta patrocinada por la Asamblea Ciudadana Ambiental de Gualeguaychú, contra la construcción de la pastera de Botnia en Fray Bentos (territorio uruguayo). ${ }^{26}$

Resumiendo. En el momento de locura se combinan diversos libretos, aunque destaca el emergente, sobre todo cuando es mayor la inestabilidad políticoinstitucional y socioeconómica, y los canales establecidos e incluso los aliados institucionales, no parecen satisfacer las demandas reactivas que se producen como respuesta a los ajustes y políticas socioeconómicas. Al inicio del ciclo, cuando aún no se han deteriorado estos canales institucionales de representación de intereses y cuando empiezan a restablecerse al final del periodo, el modelo clásico es el relevante. Así, y usando el esquema de Hirschman (1970), en estos periodos prevalece la $v o z$ en la calle, o al menos la forma clásica de hacerla valer: es la dramatización contenida de la contienda política. En tanto que en el momento de locura prevalece la salida, el grito en la calle: la dramatización del descontento adopta patrones más de contienda transgresiva. Mientras que los PP aparecen, sobre todo, cuando surgen posibilidades de cambio en la composición de las élites (elecciones).

Ahora bien, ¿de qué manera se distribuyen los libretos de la contienda en el territorio nacional? ¿Existen pautas concretas en la distribución de los libretos? Nos interesa sobre todo indagar en el efecto de cercanía o lejanía respecto de las autoridades nacionales, por un lado, y de las locales y provinciales, por otro.

Para eso hemos realizado un análisis de contingencia que nos lleve a visualizar la distribución de eventos de protesta en el territorio tomando como referencia la variable lugar — en el que ocurre el evento- codificada en las categorías Capital Federal y Resto del País. En la primera se localiza el target nacional, pues allí residen el Ejecutivo del gobierno de la república y las dos

26 Más detalles en Giarraca (2007). 
cámaras (Diputados y Senadores) del Congreso de la Nación; en la segunda aplican los territorios provinciales.

Sin duda, las características demográficas de Argentina ${ }^{27}$ imprimen rasgos específicos a su mapa de la contienda política. Es claro que la densidad poblacional de Capital Federal explica la mayor probabilidad (estadística) de ocurrencia de eventos contenciosos debido al mayor potencial de conflicto y a la mayor concentración de recursos de movilización. Sin embargo, los análisis muestran que la distribución de los libretos de contienda no es aleatoria y presenta una pauta específica.

El análisis de contingencia de la tabla 9 muestra que el libreto clásico se distribuye de modo más o menos regular en todo el territorio, aunque con mayor incidencia en las provincias; sin embargo, los residuos ajustados manifiestan que esta relación no es significativa y por tanto se confirmaría la independencia de estas categorías. Por otro lado, el libreto emergente (mayoritario en este ciclo), ha sido más recurrente en los territorios provinciales donde se localizan las sedes de la casi totalidad de los targets subnacionales. En cuanto al libreto cívico y el institucional, se desarrollan preponderantemente en Capital Federal. En los tres últimos casos, además de la distribución observada, los estadísticos demuestran que la relación territorio-libreto, tal como se ha expuesto, posee un nivel de confianza del 95\%, lo que permite confirmar su interdependencia en el sentido expuesto.

En definitiva, el 35\% de los eventos de protesta en estudio se han dado en Capital Federal, y se trata sobre todo de protesta del tipo cívico e institucional, ello se explica en parte porque es allí donde se localizan las principales administraciones y sedes políticas del gobierno del Estado nacional. En este sentido, conviene destacar que la política argentina tiene un claro e histórico rasgo de concentración institucional en Buenos Aires, lo que provoca que esta ciudad permita amplificar eficazmente los contenidos de la contienda hacia el interior y hacia el exterior del país, debido a que los medios de comunicación masiva tienen puesta su atención en lo que ocurre en este territorio. Así, los mв y los pP prefieren escenificar sus protestas en este territorio, en especial cuando sus demandadas son antagónicas. Ello revela una dinámica de nacionalización del conflicto social, y una mayor presencia de los pp de izquierdas como agentes promotores de protesta (Natalucci, 2010). De hecho, una mirada diacrónica de los libretos cívico e institucional (gráfico 4) confirman que la intensificación de la interacción contenciosa de estos actores con el target nacional se da a partir de 2001 (Natalucci, 2010: p. 101).

27 En la Ciudad Autónoma de Buenos Aires y el Conurbano Bonaerense viven trece millones de personas, que equivalen al 33\% del total del país, y a una densidad de $2360 \mathrm{hab} / \mathrm{km}^{2}$, en un país cuya densidad media es de $14.4 \mathrm{hab} / \mathrm{km}^{2}$. 
Tabla 9. Localización de los eventos de protesta, según libretos de la dramatización contenciosa

\begin{tabular}{lllllc}
\hline \multirow{2}{*}{ Localización } & \multicolumn{3}{c}{ Libretos } & Total \\
\cline { 2 - 5 } & Clásico & Emergente & Cívico & Institucional & \\
\hline Capital Federal & $31.70 \%$ & $36.70 \%$ & $25.60 \%$ & $6.00 \%$ & $100.00 \%$ \\
& $(-0.3)$ & $(-3.8)$ & $(2.9)$ & $(4.1)$ & 1111 \\
Resto del país & $32.20 \%$ & $43.80 \%$ & $21.10 \%$ & $3.00 \%$ & $100.00 \%$ \\
& $(0.3)$ & $(3.8)$ & $(-2.9)$ & $(-4.1)$ & 2098 \\
Total & $32.00 \%$ & $41.30 \%$ & $22.60 \%$ & $4.10 \%$ & $100.00 \%$ \\
\hline
\end{tabular}

$\mathrm{N}=3209$. Porcentajes horizontales (residuos ajustados). Chi-cuadrado de Pearson: 31.671.

Fuente: Elaboración propia con información de BdDP 1998-2005

Finalmente, el 65\% de los eventos de protesta se distribuyen en el resto del país con especial incidencia en la provincia de Buenos Aires donde se concentra el 35\%. Le siguen las provincias de Córdoba y Santa Fe, ${ }^{28}$ con 7\% de eventos cada una. También destacan del resto, en cuanto a los niveles de conflictividad, Tucumán y Neuquén con el $5 \%$ de los eventos de protesta producidos en el interior del país. Esta última es un caso particular y ejemplificador dado que, a diferencia de las demás provincias, no cabe asociar su alto nivel de dramatización de la contienda al alto potencial de conflicto derivado de la densidad poblacional. Neuquén tiene un rasgo particular y sostenido en el tiempo, por un lado la larga pervivencia de un gobierno regional (Movimiento Popular Neuquino) sin representatividad en el ámbito nacional; por otro, su alta dependencia del gasto público estatal, lo que la vuelve profundamente frágil frente a los recortes presupuestarios y la descentralización de funciones de servicios públicos no acompañados de coparticipación financiera (Favoro et al., 2006). En otras palabras, podemos decir que en general opera un mecanismo de obstrucción del acceso al centro (Navarro, 1999) que, como oportunidad política, facilita la promoción de eventos de protesta con un perfil emergente.

En definitiva, es en el interior donde se localizan los eventos de protesta con libreto emergente producidos fundamentalmente por мв y con demandas reactivas que se interponen a los actores subnacionales. En tal dirección, algunos estudios ponen de relieve que las dinámicas particulares de la protesta en las provincias se explican por las relaciones de los gobiernos nacional y subnacionales en relación con la asignación y distribución de recursos económicos (Moscovich, 2012). Esto confirma la tesis de Tilly (2006) respecto de que la capacidad de los gobiernos (junto a los niveles de democracia) para responder a las demandas es una de las variables que se debe atender para ex-

28 Córdoba y Santa Fe, junto a Buenos Aires, concentran el 60\% de la población del país. 
plicar la contienda política. En concreto, y en particular en contextos de crisis, cuando las características económicas y productivas de una región se fragilizan, la capacidad de los gobiernos provinciales y locales de distribuir recursos económicos de asistencia social provenientes de la nación, explicaría la mayor propensión de los movimientos ciudadanos a producir protestas sociales. En otros términos, el gobierno nacional puede habilitar o no recursos que constituyan beneficios de asistencia pública para que los gobiernos locales pudieran distribuir mediante redes de apoyo de tipo clientelar (Delamata, 2002). Así pues, las alianzas y sintonías de los gobiernos provinciales y locales con el nacional son las claves que pueden facilitar o inhibir la promoción de eventos de protesta que se desarrollan siguiendo un libreto emergente.

\section{Conclusiones}

Con este trabajo hemos querido mostrar que la dramatización de la contienda no aparece azarosa en cuanto a los actores, demandas y focos a los que se dirige. Entre estos elementos existen ciertas conexiones y relaciones que permiten hablar de modelos de libretos de la dramatización de la contienda política (diferentes combinaciones de sus componentes: quién, qué y a quién de la protesta). No se trata de que aparezcan diferentes actores, demandas y focos, sino que lo hacen de forma pautada, con una lógica interna propia que relaciona estos tres elementos.

En buena medida, es la estructura organizativa del actor que protesta la que orienta esta combinación y ello tiene que ver con sus recursos externos e internos y, por ello, con la capacidad o eficacia potencial del grupo en el desarrollo de diversas estrategias en ámbitos concretos.

Así pues, según nuestros hallazgos, los GI dirigen su protesta proactiva principalmente a un target nacional. Se trata del libreto clásico de acción colectiva ya tratado por Garretón (2001). En esa misma línea, hemos confirmado empíricamente la existencia de un modelo emergente centrado en los MB con demandas reactivas que orientan su protesta al target subnacional y que hemos denominado libreto emergente. De algún modo, ambos tipos de modelos ya se encuentran en la literatura específica donde se profundiza en las transformaciones operadas a nivel de estructura de oportunidades políticas, por un lado, y socioeconómicas, por otro, para explicar las mutaciones en la acción colectiva ciudadana (Garretón, 2001; Farinetti, 2002). También hemos confirmado una variante de ese modelo emergente, en el que los мв orientan su demanda antagónica a actores nacionales y supranacionales, se trata de protesta de corte ciudadano que hemos llamado libreto cívico. Finalmente, hemos comprobado la presencia 
de un modelo de acción colectiva contenciosa propio de los PP, con demandas antagónicas que se orientan selectivamente a actores nacionales y supranacionales; se trata de estrategias de la exposición de posiciones políticas en ámbitos extraparlamentarios y demostraciones de apoyos y "músculo". Estos apoyos, aunque minoritarios, son de alto interés analítico y los hemos denominado libreto outside-institucional.

Tabla 10. Los tipos de libretos y sus contextos

\begin{tabular}{|c|c|c|c|c|c|}
\hline \multicolumn{3}{|c|}{$\begin{array}{l}\text { Dramatización de la contienda política } \\
\text { (eventos de protesta) }\end{array}$} & \multirow{3}{*}{ Año } & \multicolumn{2}{|c|}{$\begin{array}{l}\text { Cronología } \\
\text { (acontecimientos/situaciones destacadas) }\end{array}$} \\
\hline \multirow{2}{*}{$\begin{array}{l}\text { Frecuencia } \\
\%\end{array}$} & \multicolumn{2}{|r|}{ Libretos } & & \multirow{2}{*}{ Política - Economía } & \multirow{2}{*}{$\begin{array}{l}\text { Dramatización de la contienda } \\
\text { (ejemplos) }\end{array}$} \\
\hline & Modal & Complementario & & & \\
\hline 5.0 & & Clásico & 1998 & Crisis del menemismo. & $\begin{array}{l}\text { Protesta sindicales vinculadas } \\
\text { al MTA y CTA. }\end{array}$ \\
\hline 11.7 & & & 1999 & $\begin{array}{l}\text { Fortaleza de la Alianza. } \\
\text { Elecciones presidenciales. }\end{array}$ & $\begin{array}{l}\text { Protestas de los sindicatos del } \\
\text { MTA y CTA. }\end{array}$ \\
\hline 12.2 & & $\begin{array}{l}\text { Clásico } \\
\text { Partidos }\end{array}$ & 2000 & $\begin{array}{l}\text { Cambia el mapa de fragmenta- } \\
\text { ción vertical } \\
\text { (mayoría de gobernadores } \\
\text { peronistas). } \\
\text { Nuevos ajustes estructurales. }\end{array}$ & Protestas contra el FMI. \\
\hline 17.8 & & Cívico & 2001 & $\begin{array}{l}\text { Crisis de gobierno. .. Dimi- } \\
\text { siones, } \\
\text { Ley de Déficit } 0 . \text { Superpoderes } \\
\text { a Cavallo. } \\
\text { Siete presidentes. }\end{array}$ & $\begin{array}{l}\text { Protestas del sector público. } \\
\text { Argentinazo. }\end{array}$ \\
\hline 20.2 & $\frac{0}{\frac{0}{5}}$ & Cívico & 2002 & $\begin{array}{l}\text { Represiones policiales. } \\
\text { Gobierno de Duhalde } \\
\text { (fusilamientos de piqueteros en } \\
\text { Avellaneda). }\end{array}$ & $\begin{array}{l}\text { Piqueteros, ahorristas, Asam- } \\
\text { bleas vecinales en la calle. }\end{array}$ \\
\hline 12.3 & है & Partidos & 2003 & $\begin{array}{l}\text { Elecciones presidenciales. } \\
\text { Gobierno de Kirchner. } \\
\text { Guerra en Irak. } \\
\text { Comienza una política } \\
\text { monetaria de incentivo a la } \\
\text { exportación. }\end{array}$ & $\begin{array}{l}\text { Campañas antiglobalización } \\
\text { y contra la guerra en Irak. }\end{array}$ \\
\hline 13.2 & & Cívico & 2004 & $\begin{array}{l}\text { Se anulan las leyes de Obe- } \\
\text { diencia Debida y Punto Final. } \\
\text { Crecimiento del PBI. } \\
\text { Tragedia de Cromañón. }\end{array}$ & $\begin{array}{l}\text { Campaña de protesta en San } \\
\text { Luis contra el gobernador } \\
\text { Alberto Rodríguez Saá. } \\
\text { Campaña de protesta en San- } \\
\text { tiago contra la gobernadora. } \\
\text { Campañas por el esclareci- } \\
\text { miento de crímenes. }\end{array}$ \\
\hline 7.6 & & Clásico & 2005 & $\begin{array}{l}\text { Juicio a los responsables de } \\
\text { crímenes de lesa humanidad } \\
\text { durante la dictadura militar. } \\
\text { Juicio político al jefe de Estado } \\
\text { de Capital Federal. }\end{array}$ & $\begin{array}{l}\text { Diversas campañas en reclamo } \\
\text { de recomposición salarial. } \\
\text { Toma del puente internacional } \\
\text { que une Argentina y Uruguay. }\end{array}$ \\
\hline
\end{tabular}

Nota: En la columna "Frecuencia" se recoge el porcentaje de eventos sobre el total para ese año.

Fuente: Elaboración propia.

En otras palabras, los mecanismos que subyacen a los libretos tienen que ver con las metamorfosis a nivel de oportunidad de los actores y en cuyo con- 
texto desarrollan estrategias atendiendo a sus recursos, capacidades y ámbitos de influencia. Pero también hemos visto que la aparición de los distintos tipos de libreto se relaciona con diferentes circunstancias o contextos. No solo existe una lógica interna que relaciona los elementos del libreto, sino también otra externa que los promueve. Se trata de quién, qué, a quién... y cuándo (tabla 10). ${ }^{29}$ Esta cuestión debe explorarse y la agenda de investigación de los movimientos sociales ofrece una amplia gama de modelos analíticos para analizar este asunto. Pero además creemos que el libreto condicionará la forma que adquiera la protesta social, es decir, la selección de una performan$c e$ de protesta de entre el repertorio contencioso con el que cuentan los activistas sociales vendrá orientada tanto por los factores contextuales, como por la naturaleza de la combinación entre los elementos de la promoción del evento de contienda. En otras palabras, nuestra hipótesis es que este hallazgo, los libretos, puede aportar elementos analíticos a la comprensión del cómo se protesta, y con ello a la explicación de la intensidad que adquiera un episodio de protesta, tal como un ciclo de protesta. Se trataría de reconstruir los mecanismos de la puesta en escena de la protesta que es la dirección en la que se viene trabajando.

Aquí hemos tratado de aportar un modelo y una metodología para el análisis sistemático de la relación entre los elementos internos de la promoción de un evento de protesta en la forma de libreto de la contienda política.

\section{Referencias}

Artese, M. (2012). Violencia política y protesta social en la Argentina de fin de siglo. Un Estudio Aplicado a los Cortes de Ruta. Espiral, Estudios Sobre Estado y Sociedad, XIX(52), 171-193. Recuperado de http://www.redalyc.org/pdf/138/13824291006.pdf

Artese, M. (2011). La protesta social y sus representaciones en la prensa argentina entre 1996 y 2002. Perfiles Latinoamericanos, 19(38), 89-114. Recuperado de http://www.redalyc.org/ articulo.oa?id=11519271004

Bustelo, E. \& Minujin, A. (1997). La política social esquiva. Revista de Ciencias Sociales, (6), 67-55.

Camou, A. (2000). ¿Del bipartidismo al bialiancismo? Elecciones y política en la Argentina posmenemista. Perfiles Latinoamericanos, 8(16), 11-30. Recuperado de http://www.redalyc .org/articulo.oa?id=11501601

29 En la tabla solo se muestran los acontecimientos o situaciones más sobresalientes. 
Cavarozzi, M. (1991). Más allá de las transiciones a la democracia en América Latina. Revista de Estudios Políticos, (74), 85-111.

Clemens, E. (1999). La organización como marco: identidad colectiva y estrategia política en el movimiento socialista norteamericano. En McAdam, D., McCarthy, J. \& Zald, M. (Eds.). Movimientos sociales: Perspectiva comparada (pp. 288-319). Madrid: Istmo.

Delamata, G. (2002). De los «estallidos» provinciales a la generalización de las protestas en Argentina. Perspectiva y contexto en la significación de las nuevas protestas. Nueva Sociedad, (182), 121-138. Recuperado de http://search.proquest.com/docview/748684132

Earl, J., Martin, A., McCarthy, J., Soule, S. (2004). The Use of Newspaper Data in the Study of Collective Action. Annual Review of Sociology, 30, 65-80. Recuperado de http://www .annualreviews.org/doi/abs/10.1146/annurev.soc.30.012703.110603

Farinetti, M. (2002). La conflictividad social después del movimiento obrero. Nueva Sociedad, (182), 64-75.

Farinetti, M. (1999). ¿Qué queda del “movimiento obrero”? Las formas del reclamo laboral en la nueva democracia argentina. Trabajo y Sociedad, 1(1). Recuperado el 14 de abril de 2015, de http://www.unse.edu.ar/trabajoysociedad/Zmarina.htm

Farinetti, M. (1998). Clientelismo y protesta: cuando los clientes se rebelan. Apuntes de Investigación del CECyP, II(2/3).

Ferreira Rubio, D. \& Goretti, M. (1998). Executive Decree Authority. En Carey, J. \& Shugart, M. (Eds.). When the President Governs alone: The Decretazo in Argentina 1989-1993 (pp. 33-61). Cambridge: Cambridge University Press.

Gamson, W. (1975). The Strategy of Social Protest. (2a ed.). Belmont, California: Wadsworth Publishing Company.

Garreton, M. A. (2001). Cambios sociales, actores y acción colectiva en América Latina. Santiago de Chile: Cepal/eclac. (Serie Políticas Sociales, núm. 56).

Giarracca N. (2007). La Asamblea de Gualeguaychú: su lógica de nuevo movimiento social y el sentido binacional «artiguista» de sus acciones. Realidad Económica, 22(6), 101-26.

Giarracca N. \& Gras, C. (2001). Conflictos y protestas en la Argentina de finales de siglo xx. En Giarraca, N. (Ed.). La protesta social en la Argentina. Transformaciones económicas y crisis sociales en el interior del pais (pp. 117-142). Buenos Aires: Alianza.

Giner, S. \& Pérez Yruela, M. (1979). La sociedad corporativa. Madrid: cis. 
Hardin, R. (1991). Acting Together, Contributing Together. Rationality and Society, (3), 365-380.

Herrera, M. R. (2010). Dramatización de la contienda politica: acción colectiva y protesta en Argentina (1998-2005). Tesis doctoral. Universidad Pablo de Olavide.

Herrera, M. R. (2008). La Contienda Política en Argentina 1997-2002: Un Ciclo de Protesta. América Latina Hoy, (48), 165-189.

Hirschman, A. (1970). Exit, Voice, and Loyalty: Responses to Decline in Firms, Organizations, and States. Cambridge, MA: Harvard University Press.

Inglehart, R. (1977). The Silent Revolution: Changing Values and Political Styles among Western Publics. Princeton: Princeton University Press.

Jenkins, J. \& Klandermans, B. (1995). The Politics of Social Protest. En Jenkins, J. \& Klandermans, B. (Eds.). The Politics of Social Protest. Comparatives on States and Social Movements (pp. 3-13). Mineápolis: University of Minnesota.

Jiménez, J. P. \& Cetrángolo, O. (2004). Las relaciones entre niveles de gobierno en Argentina. Revista de la CEPAL, 84, 117-134.

Klandermans, B. (1989). Introduction: Social Movement Organizations and the Study of Social Movements. En Klandermans, B. (Ed.). International Social Movement Research (1-17). Connecticut: Jai Press Inc.

Klandermans, B., Goslinga, S., McAdam, D., McCarthy, J. \& Zald, M. (1999). Discurso de los medios, publicidad de los movimientos y la creación de marcos para la acción colectiva: ejercicios teóricos y empíricos sobre la construcción de los significados. En McAdam, D., McCarthy, J. \& Zald, M. (Eds.). Movimientos sociales: Perspectiva comparada (pp. 442-475). Madrid: Istmo.

Knoke, D. (1990). Networks of Political Action: Towards Theory Construction. Social Forces, (68), 1041-63.

Knoke, D. \& Prensky, D. (1984). What Relevance do Organization Theories have for Voluntary Associations? Social Science Quarterly, 65(4), 3-20.

Koopmans, R. \& Rucht, D. (2002). Protest Event Analysis. En Klandermans, B. \& Staggenborg, S. (Eds.). Methods of Social Movement Research (pp. 231-259). Minnesota: University of Minnesota Press.

Laclau, E. (2005). La razón populista. Buenos Aires: Fondo de Cultura Económica. 
Lanzaro, J. (2001). Tipos de presidencialismo y coaliciones políticas en América Latina. En Lanzaro, J. (Ed.). Tipos de presidencialismo y modos de gobierno en América Latina (pp. 12-50). Buenos Aires: CLACSO.

Lipsky, M. (1965). Protest and City Politics. Chicago: Rand McNally \&Co.

Lo Vuolo, R. \& Barbeito, A. (1998). La nueva oscuridad de la política social. Del estado populista al neoconservador. Buenos Aires: Miño y Dávila.

Maceira, V. (2011). Orientaciones relativas a la organización sindical y la acción colectiva entre trabajadores argentinos. Perfiles Latinoamericanos, 19(38), 145-171. Recuperado de http:// www.scielo.org.mx/scielo.php?pid=S0188-76532011000200006\&script=sci_arttext

Martí i Puig, S. (2002). Nuevos movimientos sociales. Un breve estado de la cuestión. En Ibarra, P., Martí i Puig, S. \& Goma, R. (Eds.). Creadores de democracia radical. Movimientos Sociales y redes de politicas públicas (pp. 23-56). Barcelona: Icaria.

McAdam, D. (1999). Marcos interpretativos y tácticas utilizadas por los movimientos: dramaturgia estratégica en el movimiento americano pro-derechos civiles. En McAdam, D., McCarthy, J. \& Zald, M. (Eds.). Movimientos sociales: Perspectiva comparada (pp. 475-496). Madrid: Istmo.

McAdam, D., Tarrow, S. \& Tilly, Ch. (2005). Dinámica de la contienda política. Barcelona: Hacer.

McCarthy, J. (1999). Adoptar, adaptar e inventar límites y oportunidades. En McAdam, D., McCarthy, J. \& Zald, M. (Eds.). Movimientos sociales: Perspectiva comparada (pp. 205-220). Madrid: Istmo.

Moscovich, L. (2012). From Top To Bottom (and Back To The Top Again): Federal Spending, Sub-national Coalitions, and Protests in Argentina, 2002-2006 De arriba abajo (y vuelta arriba otra vez). Gasto federal, coaliciones subnacionales y protesta en Argentina, 20022006. Journal of Politics in Latin America, 4(1), 35-72. Recuperado de https://doaj.org/arti cle/560d1985d087424b8c9e82882198134b

Murillo, V. (1997). La adaptación del sindicalismo argentino a las reformas del mercado en la primera presidencia de Menem. Desarrollo Económico, 37(147), 419-446.

Natalucci, A. (2010). ¿Nueva gramática política? Reconsideraciones sobre la experiencia piquetera en la Argentina reciente. Astrolabio. Nueva Época, (5). Recuperado de https://doaj.org/ar ticle/6541c80f47d1484d9a7ca421f0af764b

Navarro, C. J. (1999). El sesgo participativo, Madrid: Ediciones del csic. 
Novaro, M. (2001). Presidentes, equilibrios institucionales y coaliciones de gobierno en Argentina (1989-2000). En Lanzaro, J. (Ed.). Tipos de presidencialismo y coaliciones politicas en América Latina (pp. 51-100). Buenos Aires: Clacso.

Nun, J. (1998). Populismo, representación y menemismo. En Burbano de Lara, F. (Ed.). El fantasma del populismo (pp. 49-79). Caracas: Nueva Sociedad.

Olson, M. (1965). The Logic of Collective Action: Public Goods and the Theory of Groups. Cambridge, MA: Harvard University Press.

Opp, K. (1990). Postmaterialism, Collective Action, and Political Protest. American Journal of Political Science, 34(1), 212-35.

Palermo, V. (1990). Programas de ajuste y estrategias políticas: las experiencias recientes de la Argentina y Bolivia. Desarrollo Económico, 30(119), 333-66.

Paramio, L. (2000). Problemas de la consolidación democrática en América Latina en la década de los 90. En Moya, Pérez-Agote \& Salcedo (Eds.). Escritos de la teoría sociología en Homenaje Luis Rodriguez Zúñiga (pp. 847-864). Madrid: cIs.

Pasquino, G. (1996). L'Opposizione. Roma, Bari: Lazaterza.

Rossi, F. (2005). Aparición, auge y declinación de un movimiento social: Las Asambleas Vecinales y Populares de Buenos Aires, 2001-2003. European Review of Latin American and Caribbean Studies, (78), 67-88.

Rucht, D. (1999). El impacto de los contextos nacionales sobre la estructura de los movimientos sociales: un estudio comparado transnacional entre movimientos. En McAdam, D., McCarthy, J. \& Zald, M. (Eds.). Movimientos sociales: Perspectiva comparada (pp. 262-287). Madrid: Istmo.

Santella, A. \& Scodeller, G. (2012). Ciclos de Protestas sin Situaciones Revolucionarias, Argentina 1958-1969-2001. En Lachenal C. \& Pirker, K. (Coords.). Movimientos sociales, derechos y ciudadanias en América Latina (pp. 79-99). Barcelona: Gedisa.

Schmitter, P. (1974). Still the Century of Corporatism? Review of Politics, 36(1), 85-131.

Schuster, F. \& Pereyra, S. (2001). La protesta social en la Argentina democrática. Balance y perspectivas de una forma de acción política. En Giarraca, N. (Ed.). La protesta social en la argentina. Transformaciones económicas y crisis sociales en el interior del pais (pp. 41-64). Buenos Aires: Alianza. 
Sidicaro, R. (2004). La crisis del Estado y los actores politicos y socioeconómicos en la Argentina (1989-2001). Buenos Aires: Uba/Libros del Rojas.

Silva Abelenda, B. M. (2015). La coalición de la Alianza en Argentina (1999-2001): un caso entre bloques. Perfiles Latinoamericanos, 23(45), pp. 31-58. Recuperado de http://www .scielo.org.mx/scielo.php?pid=S0188-76532015000100002\&script=sci_arttext

Tarrow, S. (1990). Dimocrazia e Disordine: movimimenti di protesta e politica in italia: 19651975. Roma: Libri de tempo la terraza.

Tarrow, S. (1997). El poder en movimiento: los nuevos movimientos sociales, la acción colectiva y la politica. Madrid: Alianza Universidad.

Tarrow, S. (1999). Estado y oportunidades: la estructuración política de los movimientos sociales. En McAdam D., McCarthy, J. \& Zald, M. (Eds.). Movimientos sociales: perspectivas comparadas (pp. 71-99). Madrid: Istmo.

Tilly, Ch. \& Tarrow, S. (2006). Contentious Politics. Herndon: Paradigm Publishers.

Tilly, Ch. (2008). Contentious Performances. Cambridge: Cambridge University Press.

Vázquez, D. \& Falleti, V. (2007). Política económica, deslegitimación democrática y reconstrucción social en Argentina. Perfiles Latinoamericanos, 14(27), pp. 71-109. Recuperado de http://www.redalyc.org/articulo.oa?id=11502903

Voss, K. (1999). El colapso de un movimiento social: estructuras de movilización, creación de marcos interpretativos y oportunidades políticas en el caso de los Knightz of Labor. En McAdam, D., McCarthy, J. \& Zald, M. (Eds.). Movimientos sociales: Perspectiva comparada (pp. 320-365). Madrid: Istmo.

Zolberg, A. (1972). Moments of Madness. Politics and Society, 2(2), 183-207.

Recibido el 7 de septiembre de 2015. Aceptado el 15 de Julio de 2016. 